Lima, 14-16 de junio

\title{
Coloquio internacional «Nuevas miradas sobre el régimen militar de Velasco Alvarado»
}

Lima, 14-16 de junio

\section{Gérard Borras}

\section{OpenEdition}

\section{Journals}

Edición electrónica

URL: http://journals.openedition.org/bifea/8029

DOI: 10.4000/bifea.8029

ISSN: 2076-5827

\section{Editor}

Institut Français d'Études Andines

\section{Edición impresa}

Fecha de publicación: 1 agosto 2016

Paginación: 359-360

ISSN: 0303-7495

\section{Referencia electrónica}

Gérard Borras, « Coloquio internacional «Nuevas miradas sobre el régimen militar de Velasco Alvarado» », Bulletin de l'Institut français d'études andines [En línea], 45 (2) | 2016, Publicado el 15 diciembre 2016, consultado el 07 noviembre 2020. URL : http://journals.openedition.org/bifea/8029 ; DOI : https://doi.org/10.4000/bifea.8029

Les contenus du Bulletin de l'Institut français d'études andines sont mis à disposition selon les termes de la licence Creative Commons Attribution - Pas d'Utilisation Commerciale - Pas de Modification 4.0 International. 
Événements

COLOQUIO INTERNACIONAL «NUEVAS MIRADAS SOBRE EL RÉGIMEN MILITAR DE VELASCO ALVARADO»

Lima, 14-16 juin

El Instituto Francés de Estudios Andinos (UMIFRE 17-USR-CNRS 3337 América Latina), en el marco de sus actividades científicas dedicadas a la historia contemporánea del Perú, organizó una serie de eventos sobre el periodo del gobierno de Juan Velasco Alvarado (1968-1975). El reto histórico ha sido y sigue siendo importante, pero no estuvo exento de problemas ya que este periodo, hasta hoy en día, está sujeto a lecturas radicales entre partidarios y oponentes.

El gobierno militar inició su gestión con la implementación de una reforma agraria que llevó a la expropiación de miles de grandes y medianos propietarios. También fundó un sistema de cooperativas cuya mala gestión provocó un fracaso rotundo de la experiencia. La Junta militar creó un sólido instrumento de propaganda y buscó controlar los medios hasta el punto de expropiar y nacionalizar los más potentes órganos de prensa. Para las poderosas familias peruanas que gozan todavía de sólidas posiciones sociales, estas dos medidas simbolizan hasta hoy la mala gestión del gobierno militar.

Son evidentes los errores e incompetencias del gobierno de Velasco Alvarado. Sin embargo, a nivel histórico no se puede asimilar este periodo a sus fracasos. Cuarenta años después, es legítimo retomar el análisis tomando en cuenta las rupturas logradas: la crítica de una sociedad inmovilizada, el papel de la mujer en la sociedad, la revalorización de las prácticas culturales en sectores sociales de origen andino (el quechua se vuelve idioma oficial), etc.

El Instituto Francés de Estudios Andinos logró el apoyo significativo de instituciones académicas. Se trataba de evidenciar dos aspectos: que la temática interesaba a un abanico muy amplio de instituciones e investigadores y que algunas de ellas, ligadas a sectores muy críticos, podían involucrarse y enseñar así que la importancia del análisis histórico iba más allá de las diferencias sociales y políticas. Por esta razón, la Biblioteca Nacional del Perú (BNP), la Pontificia Universidad Católica del Perú (PUCP) y el Instituto Riva-Aguëro (IRA) -que es parte de ella-, la Universidad del Pacífico (UP), la Universidad Ricardo Palma (URP), la Universidad Nacional Mayor de San Marcos (UNMSM), el Instituto de Estudios Peruanos (IEP) se unieron al IFEA para organizar varios eventos a lo largo del mes de junio de 2016.

La meta inicial era ir más allá del modelo tradicional del coloquio científico, al reagrupar a especialistas académicos sobre el tema y abrir espacios para abarcar un público amplio. Una vasta exposición fue

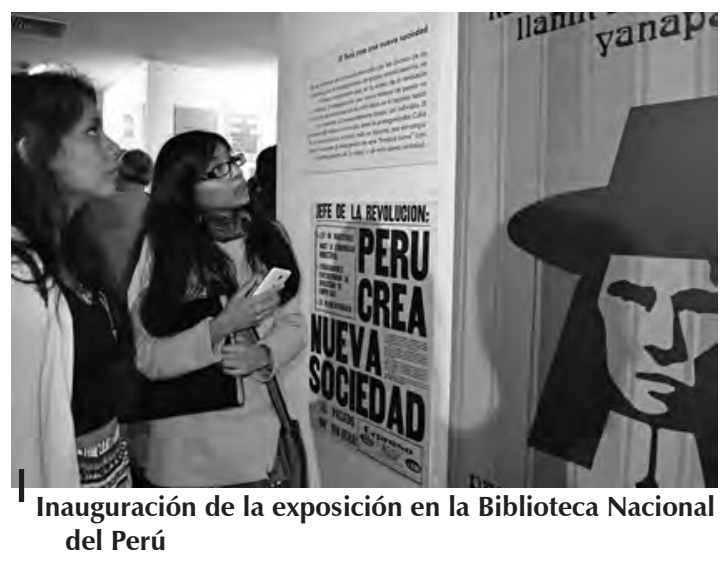

(c) Kattia Pacheco 
organizada en la Biblioteca Nacional (98 $\mathrm{m}^{2}$ con reproducciones) dedicada a la propaganda durante el gobierno de Velasco Alvarado. Un público numeroso la visitó entre el 7 y el 27 de junio de 2016.

El coloquio (Nuevas miradas sobre el régimen militar de Juan Velasco Alvarado) se desarrolló entre el 14 y el 16 de junio en tres lugares diferentes. Enrique Mayer (Yale University) dio una conferencia inaugural en el teatro Vargas Llosa de la Biblioteca Nacional delante de más de 500 personas. Esta misma noche se inauguró la exposición en presencia del director de la Biblioteca Nacional, Ramón Mujica Pinilla. En el Instituto Riva-Agüero se desarrollaron las actividades del segundo día con mesas redondas sobre la reforma agraria, la educación y el rol de los artistas e intelectuales, tema poco estudiado hasta la fecha. Dos acontecimientos merecen ser destacados este mismo día: el primero, la presentación del libro de Christabelle Roca-Rey, que analiza la propaganda visual del gobierno militar, coeditado por

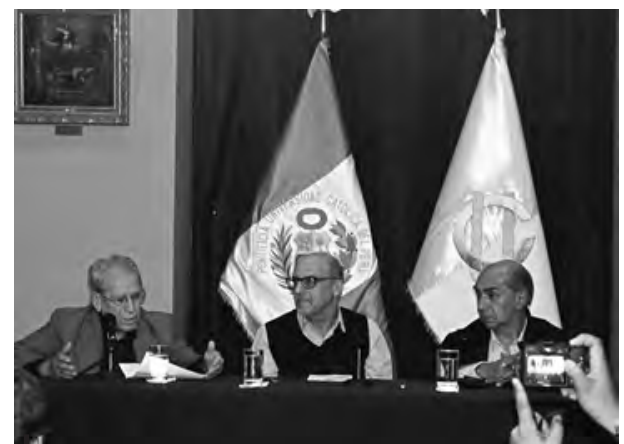

Testimonios: de izquierda a derecha, Edmundo Murrugarra, Antonio Zapata y Jesús Ruiz Durán

(C) Kattia Pacheco el Instituto de Estudios Peruanos (IEP), el IFEA y la Biblioteca Nacional, y el segundo, la mesa redonda de testigos, moderada por Antonio Zapata, que fue un acontecimiento realmente excepcional. Tres actores de peso contaron sus experiencias y sus lecturas: Edmundo Murrugarra, fundador del partido Vanguardia Revolucionaria, Jesús Ruiz Durán, artista plástico autor de los famosos afiches de propaganda alusivas a la reforma agraria y Héctor Béjar exguerrillero y actor principal del aparato gubernamental velasquista. El tercer día se desarrolló en la Universidad del Pacífico, con mesas redondas sobre el papel del ejército, las relaciones internacionales y la economía, al cual asistió un público numeroso y atento.

El objetivo se logró en gran medida: volver a tocar a nivel académico el tema del gobierno militar de Velasco Alvarado y darle una visibilidad, tal como lo evidencia la cobertura mediática del evento, sobre todo en las redes sociales. Sin embargo, la «nueva mirada» deseada por los organizadores no se completó y muchos temas y análisis tendrán que ser estudiados con mayor detalle. El IFEA demostró su capacidad para proponer a nivel académico y en el espacio social peruano temas esenciales en un país «encaminado hacia el bicentenario de su independencia (2021)». Esta fecha se impone en la agenda social, cultural y política y promueve una reflexión dinámica acerca de la construcción nacional. En este contexto, la inclusión de la historia reciente es, sin duda, un elemento esencial. Los trabajos en torno a este coloquio permitieron así contribuir a una reflexión general.

\section{Gérard BORRAS}

UMR 6258 CERHIO

Centro de investigaciones históricas del Oeste

Université Rennes2 